\title{
El profesor y el arte precolombino: creación e interdisciplinariedad en las prácticas matemáticas de identificación de regularidades y patrones
}

\section{The teacher and pre-Columbian art: creation and interdisciplinarity in mathematical practices of identification of regularities and patterns}

\author{
Nury Vargas Hernández ${ }^{2}$ \\ María José Cáceres García ${ }^{3}$
}

\section{RESUMEN}

Se asume el aprendizaje como participación, para fundamentar una investigación que inicia con procesos de innovación concerniente a las prácticas matemáticas de identificación y uso de 1

PhD Educación Matemática. Universidad de Salamanca España. Investigadora Universidad Colegio Mayor de Cundinamarca

ORCID https://orcid.org/0000-0002-8936-696X Jeannette VH jvargash@unicolmayor.edu.co

2 Maestra en Artes Plásticas. Universidad Nacional de Colombia. Investigadora Universidad Colegio Mayor de Cundinamarca. Estudiante Magister en Estética e Historia del Arte. Universidad Jorge Tadeo Lozano. Bogota ORCID https://orcid.org/0000-0002-8210-6719 nvargash@unicolmayor.edu.co

3

Doctora. Universidad de Salamanca España. Investigadora Universidad Colegio mMayor de Cundinamarca

ORCID https://orcid.org/0000-0002-0311-5810 majocac@ usal.es patrones a través de la riqueza y comprensión de la cultura precolombina en Colombia, examinándola tanto desde la matemática como desde la expresión artística.

Desde la educación matemática y con una mirada distinta a la tradicional, se determina el contexto artístico como un espacio diverso, que privilegia un trabajo interdisciplinario entre profesores, con el propósito de presentar un enfoque en la enseñanza en los primeros cursos universitarios de precálculo. Como temática transversal en estos estudios se identifican las prácticas matemáticas de identificación y uso de patrones, las cuales en las artes visuales son elementos considerados como 
una constante. Así se configura el interés en indagar sobre ¿Cómo propiciar en estudiantes de primer semestre universitario las prácticas de identificación y uso de regularidades y patrones, a través de las figuras del arte precolombino, desde las artes plásticas y la didáctica de la matemática?

Para ello se estudió la conceptualización que existe sobre comunidades de práctica, en el ámbito de la Educación Matemáticas y desde las artes visuales se examinaron las culturas precolombinas Muisca y Tairona. Se caracterizaron figuras iconos tanto por su simbología como por su posibilidad de ser analizadas; identificando semejanzas, diferencias y medidas. Se logró establecer una propuesta práctica que se formaliza a través de un taller guía, el cual se presenta detalladamente, para los profesores de precálculo de los primeros semestres Universitarios; determinaciones fundamentadas a partir de una profunda reflexión y estudio documental.

PALABRAS CLAVE: regularidades y patrones, estudiantes universitarios, arte precolombino, precálculo, comunidades de práctica.

\section{SUMMARY}

Learning is assumed as participation, in order to base an investigation that begind with innovation processes concerning the mathematical practices of identification and use of patterns, through the richness and understanding of preColumbian culture in Colombia, examining it both as a mathematical and an artistic expression.

From the perspective of mathematical education and with a different view from the traditional one, the artistic context is determined as a diverse space, which privileges an interdisciplinary work among teachers, with the purpose of presenting a focus on teaching during the first university pre-calculus courses. As a transversal theme in these studies, the mathematical practices of identification and use of patterns are identified, which, in the visual arts are elements considered as constant. This is how the interest in researching "the way to promote identification and use of regularities and patterns in freshmen university students, through pre-Columbian art figures, as seen from the visual arts and the didactics of mathematics" is configured.

\section{ABSTRACT}

Regularities and patterns, university students, pre-Columbian art, pre-calculus, communities of practice.

\section{INTRODUCCIÓN}

A partir de la literatura en Educación Matemática, según la cual, semestre tras semestre los profesores universitarios experimentan dificultades para que sus estudiantes obtengan los logros esperados y desarrollen habilidades en la consulta de los contenidos del pre cálculo, nos interesarnos en indagar sobre ¿cómo poner la interdisciplinariedad, al servicio del estudio y la creación de propuestas para la comprensión de conceptos? y puntualmente planteamos la pregunta ¿Cómo propiciar en estudiantes de primer semestre universitario las prácticas de identificación y uso de regularidades y patrones, a través de las figuras del arte precolombino, desde las artes plásticas y la didáctica de la matemática?

\section{REFERENTES}

\section{Desde la perspectiva del aprendizaje}

En esta propuesta se considera el aprendizaje como un fenómeno social y se acepta, a partir de las comunidades de práctica, la afirmación concerniente a que "nadie aprende una nueva práctica solo; la gente aprende una nueva práctica simplemente haciéndola, pero siempre 
guiada al menos por una persona con más experiencia" (Vásquez, 2011, p. 8).

Se asume aprender como sinónimo de participar, es decir, del proceso de tomar parte activa en alguna actividad, empresa o misión social, situada en un contexto particular, al mismo tiempo que se establecen relaciones con otras personas (Wenger, 1998).

En la investigación se tiene en cuenta a esta teoría social del aprendizaje como una perspectiva, no una receta que nos dice qué debemos hacer y en esta misma línea de ideas se asume que el aprendizaje no siempre requiere de la instrucción explícita, sino que, a través de la observación, escucha activa e interacción, se van igualmente adquiriendo diferentes conocimientos y habilidades.

Es así que, se usa un acercamiento en torno a las comunidades de práctica (Wenger, 2001), entendiéndolas como:

Un contexto para el aprendizaje de los principiantes a la vez que son un contexto para transformar nuevas visiones en conocimiento.

- Un contexto viviente que ofrecerá a los principiantes acceso a la competencia, provocando una experiencia personal de compromiso por la cual incorporar esa competencia a una identidad de participación.

Un compromiso mutuo en torno a una empresa conjunta.

- Un vínculo de competencia acompañado de respeto por la particularidad de la experiencia.

De allí que, en la propuesta de innovación, se pretende que los profesores se acerquen a nociones de comunidades de práctica, rastreando dos características de ellas; al seguir la huella a indicadores relacionados con la noción de participación legítima y la negociación de significados y así se permita dicha iniciación de comunidades de práctica de clase.

Para utilizar la noción de participación legítima, nos apoyamos literalmente en Camargo (2010), en cuanto a tres estados que la investigadora expone: participación periférica legítima, participación legítima y participación plena. Esta clasificación retoma una distinción, de otros investigadores, de acuerdo con el papel que desempeña el profesor y también cualificando con el término relevante, genuino, autónomo y original, así:

Relevante: esencial y útil para el cumplimiento de la meta.

Genuina: con fundamento para lo que se dice o hace y con conciencia de la responsabilidad con la tarea que se desarrolla.

Autónoma: espontánea, por iniciativa propia y por un interés personal

Original; creativa, con ideas propias.

\section{DESDE LAS ARTES PLÁSTICAS Y LAS MATEMÁTICAS}

Las regularidades son características apreciables en diferentes elementos del ambiente $\mathrm{o}$ acontecimientos, es decir las semejanzas, las diferencias, lo que permanece, lo que cambia se presenta en un orden regular. Los patrones son un tipo de regularidad, son una sucesión de signos construidos sobre un núcleo o forma que se construye siguiendo una regla. Coincidimos con investigadores quienes afirman que la idea básica de patrón surge de la repetición de una situación con regularidad (Castro 1995) y el reconocimiento de patrones es una habilidad esencial para generalizar, ya que, a partir de una regularidad observada, se 
busca un patrón que sea válido para más casos (Merino, Cañadas y Molina, 2013). Así, se tendrá en cuenta que una regularidad tiene un patrón a identificar y en casos específicos un patrón es una regularidad en una secuencia.

En las artes plásticas, los elementos susceptibles a ser vistos como patrones y regularidades pueden ser una constante. El análisis de patrones y regularidades en la iconografía precolombina se sustenta con estudios desde la arqueología y la antropología, como es el caso de Reichel - Dolmatoff, (2.005) en su búsqueda de explicación de la orfebrería y el chamanismo prehispánico, desde la biología Legast (1987) con sus estudios de la fauna precolombina parece pionera en investigación y reconocimiento de fauna en iconografía precolombina y en el diseño gráfico Grass $(1979,1982)$ por su parte pionero en presentar la figura precolombina desde los parámetros del diseño para acercarlo a una mejor comprensión y visualización de la forma.

En el acercamiento al arte precolombino y el estudio de patrones y regularidades se maneja una serie de conceptos comunes a las artes plásticas y al diseño gráfico. Read, (1990), formula la idea de que el arte intenta decir algo acerca del hombre, de su universo y del artista mismo. Equipara el conocimiento que se genera desde el arte con la forma de conocer desde la filosofía o desde la ciencia, aclarando y reconociendo que esta es una forma de conocimiento diferente. Por su parte Sondereguer (2000) explica el arte plástico como las obras elaboradas con materiales maleables desde el uso de diversas técnicas. La cualidad y calidad de obra de arte será dada en el momento en que se manifiesta su esencia expresiva, poética y cuando se hace evidente la importancia de quien la crea. Teniendo unas primeras bases de lo que es el arte y el arte plástico es importante observar lo que el arte precolombino conlleva. Según Rivadeneira (2015), en su escrito Lo maravilloso del arte indígena, lo presenta como un concepto que alude a elementos de distinta índole concebidos por las civilizaciones indígenas antes del arribo de Cristóbal Colón a lo que se llamó el Nuevo Mundo. Estos elementos, dice el investigador, han sido estudiados y en algunos casos encontrados por arqueólogos quienes los catalogan como de carácter utilitario o ritual. La propuesta de investigación al tomar la iconografía precolombina como una forma de acercar de manera natural al niño a su patrimonio y cultura desde la imagen, enfrenta el concepto cultura como el conjunto de creencias, conocimientos, técnicas y tradiciones que conforman el patrimonio de un determinado grupo social. Algunos antropólogos llaman a la cultura herencia social, porque se recibe de los antepasados. La propuesta de arte en el análisis de figuras precolombinas, los patrones son los elementos característicos o detalles formales que identifican a una pieza, los cuales, al presentarse de manera repetitiva y muy similar en otras piezas, permiten la identificación de una representación particular (e.g. el caso el hombre murciélago) o permiten ubicar la pieza dentro de una cultura específica.

En el análisis de los elementos característicos se espera usar argumentos inductivos, teniendo en cuenta que un argumento inductivo es aquel en el cual la evidencia que soportan sus premisas, supuestas todas verdaderas, hace altamente improbable que su conclusión sea falsa. La fuerza inductiva no proviene de la forma, como en el caso de la validez en los argumentos deductivos sino de la fuerza de la evidencia que contiene sus premisas y del grado de "improbabilidad" de la conclusión.

La lógica inductiva clasifica los argumentos inductivos en débiles y fuertes, según sea el grado de posibilidad de que las premisas sean verdaderas y la conclusión sea falsa (López y Betancourt, 2008). Se tiene además que los tipos más comunes de razonamiento por inducción 
son por generalización por enumeración y por analogía. Las inferencias por enumeración pueden ser de tres tipos; teniendo en cuenta el contenido genérico de sus premisas y su conclusión: de muestra a población, de muestra a muestra, o de población a muestra.

\section{MÉTODO}

Esta investigación cualitativa de carácter descriptivo se llevó a término haciendo uso de triangulación de investigadores y acudiendo a consensos a la luz de la teoría social de aprendizaje.

A partir del marco teórico de las comunidades de práctica (Wenger, 2001), se contó con un grupo de profesionales quienes, como expertos, buscaron articular un estudio desde la diversidad de conocimientos de cada uno de sus miembros, especializados en diferentes áreas; didáctica de la matemática, docencia de la matemática, artes plásticas y evaluación.
Adicional a ello, se recurrió a un acopio documental y al método heurístico a partir del cual los investigadores se apoyan en sus experiencias vivenciales desde los diferentes campos de formación tomando recursos culturales e históricos.

La mirada al problema de investigación incluyó el análisis formal de figuras antropomorfas, zoomorfas y antropozoomorfas en algunas culturas precolombinas en Colombia, sin dejar de lado la importancia de su posible explicación simbólica dentro de un contexto de enriquecimiento cultural.

Se retomó y aprovechó estudios (fuentes documentales) y mediante la triangulación de información, se argumentó la propuesta enfocada hacia la identificación y uso de regularidades y patrones en los estudiantes de los primeros semestres universitarios.

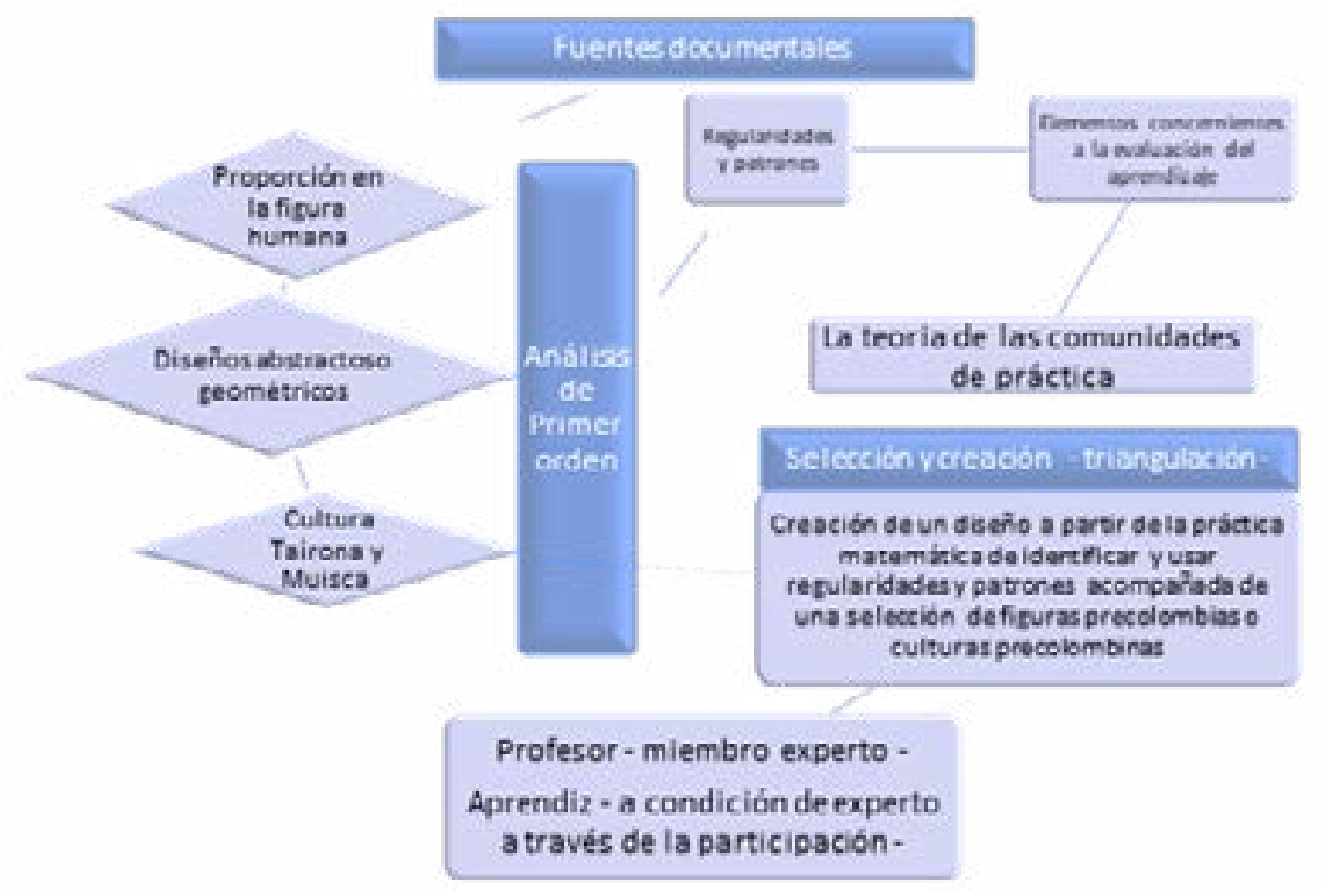


En el proceso de toma de decisiones respecto a las figuras precolombinas, se analizan, definen piezas figurativas de orfebrería precolombina en Colombia que permiten el estudio de regularidades y patrones, siendo un elemento clave el acercamiento al contexto histórico e iconográfico de las piezas como de las culturas escogidas. (Vargas, Vargas y Cáceres, 2018).

El taller, que se diseña como propuesta central, consta de un video creado desde las diferentes culturas, material explicativo con información para el profesor y un cuestionario de creación y propuesta con material visual de soporte. Para efectos de la investigación el documento es denominado Taller Regularidades y Patrones: estudio de figuras precolombinas y artes plásticas.

\section{Para la experiencia se procede a plantear:}

EMPRESA COMÚN: identificación y uso de regularidades y patrones, concretamente en figuras precolombinas y el descubrimiento $y$ uso de esta práctica en el aprendizaje de otros conceptos matemáticos

COMPROMISO MUTUO: participar en los talleres, discusiones concernientes a regularidades y patrones. Generar propuestas de identificación y uso de patrones en figuras precolombinas de otras culturas y en conceptos matemáticos.

REPERTORIO COMPARTIDO: estrategias de acercamiento a las culturas precolombinas, contextualización de lo precolombino como legado cultural, rutinas en la selección y el examen de imágenes, uso de vocabulario, desde las artes plásticas, y su tránsito a estrategias de acercamiento al uso de regularidades y patrones en lo relativo a conceptos matemáticos.

\section{PROCESO}

Respecto al concepto participación legítima concerniente a Lave y Wenger, 1991), esta propuesta, inicialmente abarca la participación relativa a la observación e intervenciones iniciales de los estudiantes frente a la gestión del experto (profesor), para luego ceder la voz a equipos de estudiantes quienes se espera que tomen la iniciativa de indagar, en este caso específico, en otras culturas precolombinas y conceptos matemáticos que impliquen regularidades y patrones.

Dicha iniciativa implica que los estudiantes intenten estrategias de acercamiento a las culturas precolombinas, se interesen por el legado cultural $\mathrm{e}$ incursionen tanto en la selección como en el análisis de las imágenes buscando vincularlas con patrones y extenderlos a conceptos como el sistema de numeración, sistema de media base diez, funciones, fractales, entre otros.

El taller está propuesto para ser rediseñado por el profesor, como experto, con sus estudiantes desde los referentes expuestos.

Es de tener presente que el proyecto se ubica en una población de estudiantes, quienes cursan primer semestre universitario. Para el profesor la intención es repensar estrategias desde las prácticas matemáticas concernientes a la identificación y uso de regularidades y patrones, que permitan exhibir argumentos inductivos y posibiliten gestionar posteriormente el aprendizaje de la noción de escala, con un enfoque que englobe un acercamiento a otra gama de elementos culturales.

\section{Pautas:}

a. Se sugiere al profesor, tomar el vídeo diseñado para el Taller como material de información teórica y visual que el estudiante pueda observar y trabajar previamente a la 
sesión en el aula, al igual que la invitación a los estudiantes a visitar el Museo de Oro.

b. A través del video se espera que el profesor exhiba una forma de realizar el examen a las figuras precolombinas, estableciendo un proceso que luego los estudiantes pueden 'copiar' e ir enriqueciendo en cuando a la práctica de identificación de patrones.

c. Se tendrá especial atención a mencionar los elementos característicos: se refiere a detalles que, por presentarse de manera repetitiva y muy similar en las piezas, permiten la identificación del icono del hombre -murciélago en la cultura Tairona. Dicha repetición y sus transformaciones son examinadas en el proceso de comprensión del significado de patrones.

d. En el análisis de los elementos característicos el profesor compartirá con los estudiantes los argumentos inductivos.

El maestro presentará los argumentos inductivos en los que en sus premisas se informa sobre el resultado de 'un conjunto de observaciones' en el que se ha detectado cierto grado de uniformidad.

Se tendrá presente que los objetos que son descritos en las premisas y constituyen una muestra del conjunto formado por todos los objetos de ese tipo, es llamado población. La conclusión puede ser una generalización sobre la población, o bien una afirmación sobre un caso particular no observado de esa misma población.

Las inferencias por enumeración pueden ser de tres tipos; teniendo en cuenta el contenido genérico de las premisas y su conclusión: de muestra a población, de muestra a muestra, o de población a muestra.

Ejemplos: - a manera del razonamiento que utilizarían los investigadores para establecer el icono del hombre murciélago -

\section{Primer ejemplo:}

La figura Precolombina tiene una representación de ser humano

En la cabeza de la figura hay un abanico semicircular.

En el rostro de la figura se distinguen ojos, nariz y boca.

La figura tiene una nariguera que eleva la nariz imitando una aleta nasal y un tembetá debajo del labio inferior.

Entonces la figura probablemente representa al hombre murciélago.

\section{Segundo ejemplo:}

La figura precolombina examinada sostiene un bastón

Esa figura es antropomorfa.

Los pies de la figura tienen forma de garras de un mamífero.

La figura en la cabeza tiene una visera con una especie de dos orejitas (tragus).

Entonces la figura puede representar al hombre murciélago.

\section{Tercer ejemplo:}

Todos los hombres murciélago observados tienen penacho que representa sus orejas. Luego la próxima figura hombre murciélago que observemos tendrá penacho que representa sus orejas.

\section{ORGANIZACIÓN}

Dentro del material del Taller están las carpetas con imágenes; se presentan en cinco grupos para generar trabajo compartido entre los estudiantes, el cual se llevará a término en la segunda sesión de taller. Están organizadas desde una figura principal de las culturas Tairona 
y Muisca, pensando en un trabajo en grupos de estudiantes donde lleguen a proponer, analizar, reforzar, descubrir los patrones en las imágenes proporcionadas. Así:

CARPETA 1 (serpiente); CARPETA 2 (murciélago); CARPETA 3 (hombre - ave); CARPETA 4 (narigueras); CARPETA 5 (tunjos).

\section{Observaciones:}

- $\quad$ Se busca que los estudiantes propongan su propio nuevo diseño precolombino con los elementos aportados y realicen una sustentación del resultado. El nuevo diseño puede surgir alterando la mayoría de las regularidades, atendiendo o mezclando características de las diversas culturas o conservando la mayoría de regularidades.

- $\quad$ Se sugiere al profesor compartir con el estudiante la bibliografía referente a los libros: "Los rostros del pasado. Diseño prehispánico colombiano", (1.982) y "Animales mitológicos" (1.979) del diseñador y artista colombiano Antonio Grass, los cuales, aunque no se mencionan en el cuerpo del Taller son de gran utilidad al estudiante al momento de proponer nuevas búsquedas de la imagen precolombina.

\section{Momentos:}

Teniendo en cuenta este proceso, se sugiere al profesor organizar el Taller en tres sesiones de dos horas cada una, de la siguiente manera:

Los estudiantes se organizarán por grupos de 4 a 5 miembros y dado que La empresa conjunta de una práctica se negocia colectiva y permanentemente y crea relaciones de responsabilidad mutua entre los participantes, no resulta posible ser totalmente descriptivos y/o prescribir la organización de las sesiones.

- $\quad$ Sesión Uno: presentación, comentarios y análisis del vídeo "Regularidades y patrones, imagen del Hombre -Murciélago en la cultura
Tairona". Reflexiones de los estudiantes frente al tema regularidades y patrones y guía por parte del profesor respecto al tema.

- $\quad$ Sesión Dos: trabajo de observación y estudio del material visual dispuesto en carpetas para ser explorado en grupos de estudiantes. Los grupos de estudiantes determinan la estrategia y uso del material informativo suministrado en los formatos del taller que intentan prestar guía en cuanto a las culturas Tairona y Muisca.

Los grupos de estudiantes intentarán llegar a un consenso sobre lo que van a proponer; los procesos de negociación de significados y la participación al interior del grupo. El proceso de generación de estrategias y examen de regularidades y patrones, serán las manifestaciones con las que cuenta el profesor para el seguimiento del aprendizaje.

- $\quad$ Sesión Tres: por grupos de trabajo, los estudiantes esbozan y crean un nuevo diseño o figura que surge desde el examen de las imágenes proporcionadas en las carpetas, para luego sustentarlo desde el tema Regularidades y Patrones, así como desde la indagación y entendimiento al cual el grupo ha llegado de lo precolombino en el arte.

Dado que, cada vez que los grupos de estudiantes hacen una presentación en clase, ellos deben llegar a un consenso sobre lo que van a proponer, los procesos de negociación de significados se concretan. Esta materialización se expresa en la información contenida en las creaciones y en las intervenciones de los miembros del grupo sustentando sus propuestas.

Dependiendo de la dinámica que se genere por grupos en la sesión dos, el profesor cuenta con autonomía de sugerir y guiar a los grupos de estudiantes para llegar preparados, a esta sesión tres, con mayor cantidad de información tanto teórica como visual. 


\section{EVALUACIÓN:}

Se recomienda tener presente, en la organización y revisión que, al considerar una organización institucional como una comunidad de práctica, interesa capturar la riqueza de las interacciones sociales y actividades no necesariamente previstas, que se desarrollan libremente en su interior, más allá de la simple estructura prefigurada (Camargo, 2010).

Para valorar el tipo de participación de los estudiantes se puede utilizar la siguiente rúbrica:

\begin{tabular}{|c|c|c|c|}
\hline & 1 & 2 & 3 \\
\hline $\begin{array}{lr}\text { Demanda } & \text { de } \\
\text { ayuda } & \text { del } \\
\text { estudiante } & \text { al } \\
\text { profesor } & \end{array}$ & $\begin{array}{l}\text { El estudiante necesita } \\
\text { a s e s o r a m i e } \mathrm{n} t \mathrm{o} \\
\text { continuado del profesor } \\
\text { para tomar decisiones }\end{array}$ & $\begin{array}{l}\text { El estudiante necesita } \\
\text { a s e s o r a m i e } \mathrm{n} t \mathrm{o} \\
\text { ocasional del profesor } \\
\text { para tomar decisiones } \\
\text { propias }\end{array}$ & $\begin{array}{l}\text { El estudiante dialoga } \\
\text { con el profesor y } \\
\text { es capaz de tomar } \\
\text { decisiones propias }\end{array}$ \\
\hline $\begin{array}{l}\text { Utilización de } \\
\text { recursos para la } \\
\text { actividad }\end{array}$ & \begin{tabular}{|ll} 
El estudiante & usa \\
únicamente los & que \\
están disponibles &
\end{tabular} & $\begin{array}{l}\text { El estudiante busca } \\
\text { nuevos recursos a partir } \\
\text { del conocimiento de los } \\
\text { que están disponibles }\end{array}$ & $\begin{array}{l}\text { El estudiante busca y } \\
\text { crea recursos de forma } \\
\text { genuina a partir del } \\
\text { conocimiento de los } \\
\text { disponibles }\end{array}$ \\
\hline Formalidad & $\begin{array}{lr}\text { El estudiante } & \text { no } \\
\text { fundamenta } & \text { sus } \\
\text { ideas y delega } & \text { su } \\
\text { responsabilidad } & \text { en } \\
\text { otros } & \end{array}$ & $\begin{array}{l}\text { Solo en ocasiones el } \\
\text { estudiante aporta ideas } \\
\text { fundamentadas yasume } \\
\text { su responsabilidad en la } \\
\text { tarea }\end{array}$ & \begin{tabular}{|lrr} 
El & estudiante & aporta \\
ideas & fundamentadas \\
y & asume & su \\
responsabilidad & en & la \\
tarea & & \\
\end{tabular} \\
\hline Relevancia & $\begin{array}{l}\text { Todas las ideas son } \\
\text { poco importantes o } \\
\text { inadecuadas para el } \\
\text { objetivo marcado }\end{array}$ & $\begin{array}{l}\text { Algunas ideas son } \\
\text { esenciales o útiles para } \\
\text { el del objetivo marcado }\end{array}$ & $\begin{array}{l}\text { Todas las ideas son } \\
\text { esenciales o útiles para } \\
\text { el del objetivo marcado }\end{array}$ \\
\hline Autonomía & $\begin{array}{l}\text { El estudiante depende } \\
\text { siempre de las ideas } \\
\text { y actitudes de los } \\
\text { compañeros o del } \\
\text { profesor }\end{array}$ & $\begin{array}{l}\text { El estudiante se apoya } \\
\text { en sus compañeros } \\
\text { y profesor para la } \\
\text { realización de tareas y } \\
\text { exposición de ideas }\end{array}$ & $\begin{array}{l}\text { El estudiante toma } \\
\text { la iniciativa para la } \\
\text { realización de tareas, } \\
\text { exposición de ideas }\end{array}$ \\
\hline Originalidad & $\begin{array}{l}\text { Las ideas están } \\
\text { copiadas de las fuentes } \\
\text { disponibles }\end{array}$ & $\begin{array}{l}\text { Las ideas están } \\
\text { parafraseadas de las } \\
\text { fuentes disponibles }\end{array}$ & $\begin{array}{l}\text { Las ideas están } \\
\text { construidas a partir } \\
\text { de la lectura de varias } \\
\text { fuentes y expresadas } \\
\text { de forma creativa. }\end{array}$ \\
\hline
\end{tabular}


A partir de la cual se considera Participación periférica legítima si la valoración media de los aspectos se encuentra en el intervalo [1,2); Participación legítima si la valoración media de los aspectos se encuentra en el intervalo $[2,3)$ y Participación plena si la valoración media de los aspectos es 3

Además, en el trabajo de los grupos observará y registrará cómo se produce la negociación de significados en las tareas que puedan ser observadas. Se espera durante el taller que el profesor pueda atender a cada uno de los grupos en varias ocasiones (dependerá del número de estudiantes participantes en el taller).

\section{CENTRO DE LA PROPUESTA: VÍDEO}

El profesor con los estudiantes después de ver el video y escuchar las explicaciones concernientes a los patrones desde las artes plásticas, los guiará en la segunda sesión permitiéndoles que sean capaces de comprometerse con la actividad, usando las carpetas de imágenes preparadas para tal fin, pudiendo así realizar un trabajo de indagación, gestando alternativas y formas de análisis, concernientes a los patrones que se presentan en dichas láminas, al igual que ingresar de manera autónoma o por consenso, en la consulta de las culturas a las cuales pertenecen las figuras precolombinas relacionadas.

El video se titula: REGULARIDADES Y PATRONES, IMAGEN DEL HOMBRE -MURCIÉLAGO EN LA CULTURA TAIRONA (Vargas, N. 2018) y es de acceso libre a través del link https://www.youtube.com/ watch?v=6uQ98wJoJdg

Se sugiere al profesor tener presente que la información presentada en el vídeo así como en el taller desde el análisis de figuras e iconos precolombinos Tairona para el estudio de patrones en esta investigación giran en torno a los estudios e investigaciones previas de Reichel -Dolmatoff (2005), Legast (1987), Lleras (2015), Gutiérrez y Torres (2009).

\section{LAS FIGURAS CENTRALES DE ANÁLISIS:}

Esta investigación, presenta una forma de examinar las figuras precolombinas estableciendo dos criterios: elementos característicos y las transformaciones de la figura base; teniendo como referentes los estudios antes citados.

En esta indagación, al hablar de elementos característicos, se refiere a detalles que, por presentarse de manera repetitiva y muy similar en las piezas, permiten la identificación, en este caso, del icono del hombre -murciélago en la cultura tairona.

Al hablar de la transformación de la figura base, nos referimos a los elementos característicos descritos en 1.1., en este caso, para el hombre murciélago pero ahora con la aparición de nuevos detalles que llevan a observar precisamente una transformación, un cambio en la figura que sugiere nuevas interpretaciones simbólicas y especialmente para esta investigación, nuevos elementos característicos para ser analizados como patrones que permiten que las piezas sean o no equiparadas con otras del grupo identificado como icono de hombre -murciélago.

\subsection{ICONO DEL HOMBRE - MURCIÉLAGO}

Figura 1, se identifican elementos característicos cuando se procede a examinar el personaje, como en el ejemplo: 
Figura 1. Pectoral Tairona, figura en oro, período Tairona, $900-1.650$

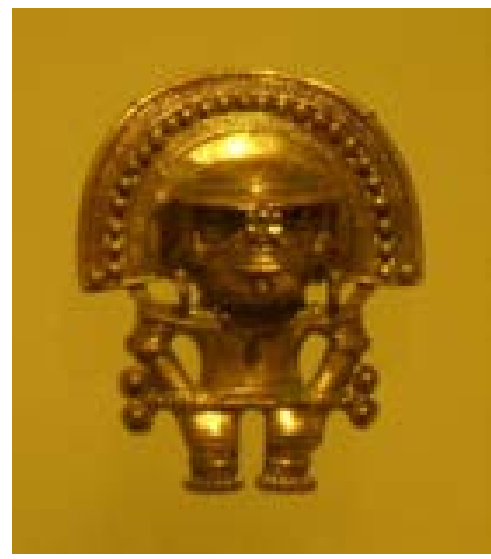

Pectoral Tairona antropozoomorfo (forma humana y animal). Los elementos característicos para tener en cuenta son:

Usualmente la cabeza se presenta más grande respecto al cuerpo, siendo éste representación de ser humano,

La cabeza por lo general también tiene una representación humana pero es la que adquiere elementos característicos vistos como patrones que llevan a reconocer la imagen del hombre murciélago.

Las extremidades superiores generalmente sostienen un bastón de mando en sentido horizontal.

Las piernas en la mayoría de las figuras sugieren que el personaje está de pie, aunque por lo general están un poco dobladas, el personaje se inclina levemente hacia el frente, sin embargo, a modo de análisis propio en esta investigación, se presenta estable y transmite idea de jerarquía.

En el rostro se distinguen ojos, nariz y boca, siendo recurrente la representación de rasgos característicos del murciélago.

En el rostro también aparecen detalles que rodean los ojos a manera de características específicas a algunas especies, una nariguera que eleva la nariz imitando la aleta nasal del murciélago, un tembetá que es un objeto tubular usado debajo del labio inferior, una visera con una especie de orejitas sobre ella, representando el tragus, un penacho a modo de tocado en la cabeza.

Figura 2. Pectoral Tairona, figura en oro, período Tairona, $900-1.650$

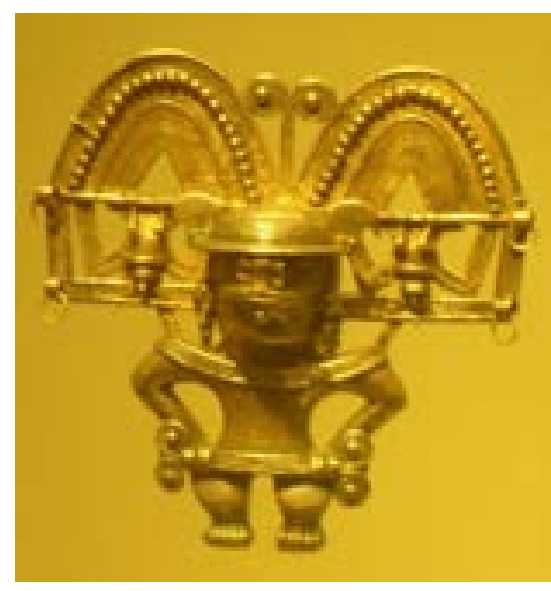

Se evidencian los elementos característicos ya establecidos, aparecen otros que son nuevos, como el caso de los murciélagos colgando a lado y lado del penacho, el cual a su vez, en este caso, se encuentra dividido en dos partes.

En otras figuras suelen aparecer dientes y colmillos que dan al rostro una expresión agresiva.

En ocasiones aparecen serpientes bífidas a lado y lado de la figura del hombre-murciélago.

En la figura 3, a partir de la figura base y la incorporación de nuevos elementos característicos se diferencia posiblemente el icono del hombre -ave del icono del hombre -murciélago. 
Figura 3. Pectoral Tairona, figura en oro, período Tairona, $900-1.650$

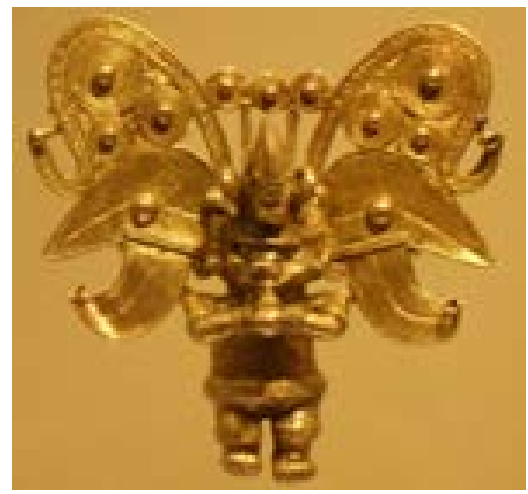

Se observa cómo el penacho de la cabeza adquiere otros elementos, posiblemente presentando aves o su plumaje y probable explicación de conexión con el mundo superior.

Es usual que en cada pieza aparezcan otros elementos ampliando su posible simbología.

Los pies, a modo de análisis propio en esta investigación, parecen ser la representación de las extremidades inferiores de un felino, lo cual llegaría a hacer referencia a la conexión con el mundo medio o terrestre, como explicación de la cosmovisión y simbología tairona.

El personaje parece conservar la nariguera para enfatizar la posible presentación de la aleta nasal del murciélago.

En este pectoral, como en otros similares es de resaltar un elemento nuevo, un instrumento musical que parece estar siendo interpretado por el chamán o personaje ataviado y el cual trae también explicaciones simbólicas desde el pensamiento tairona.

\section{INFORMACIÓN TÉCNICA DE LAS FIGURAS 1, 2 Y 3:}

Pectorales antropozoomorfos, pertenecientes al Período Tairona del año 900 al 1.650, Sierra Nevada de Santa Marta en Colombia, sus dimensiones aproximadas $7,6 \mathrm{~cm} . \times 7,6 \mathrm{~cm}$. Figuras orfebres cuya técnica es a la cera perdida fundida en tumbaga. Se encuentran en el Museo del Oro, Bogotá -Colombia.

Posterior al taller, la trayectoria que se propone es examinar el sistema de numeración y medición decimal junto con la notación científica, pasar luego al estudio de las escalas como un puente a la indagación en razones y proporciones, abordando la caracterización de las progresiones aritméticas y geométricas; con un énfasis en la mirada a regularidades y patrones.

\section{RESULTADOS}

El esbozo de talleres permitió un proceso de innovación en la asignatura de precálculo, a través de la secuencia de talleres, con unos acercamientos a comunidades de practica y con creaciones en los grupos de estudiantes, quienes a través de su participación, transforman sus observaciones, indagaciones y análisis concretándolos en la creación de nuevos patrones de repetición, tales como se señala en Vargas, Vargas (2019), en donde se reportan algunos de los procesos que seguimos en el aula, así: 

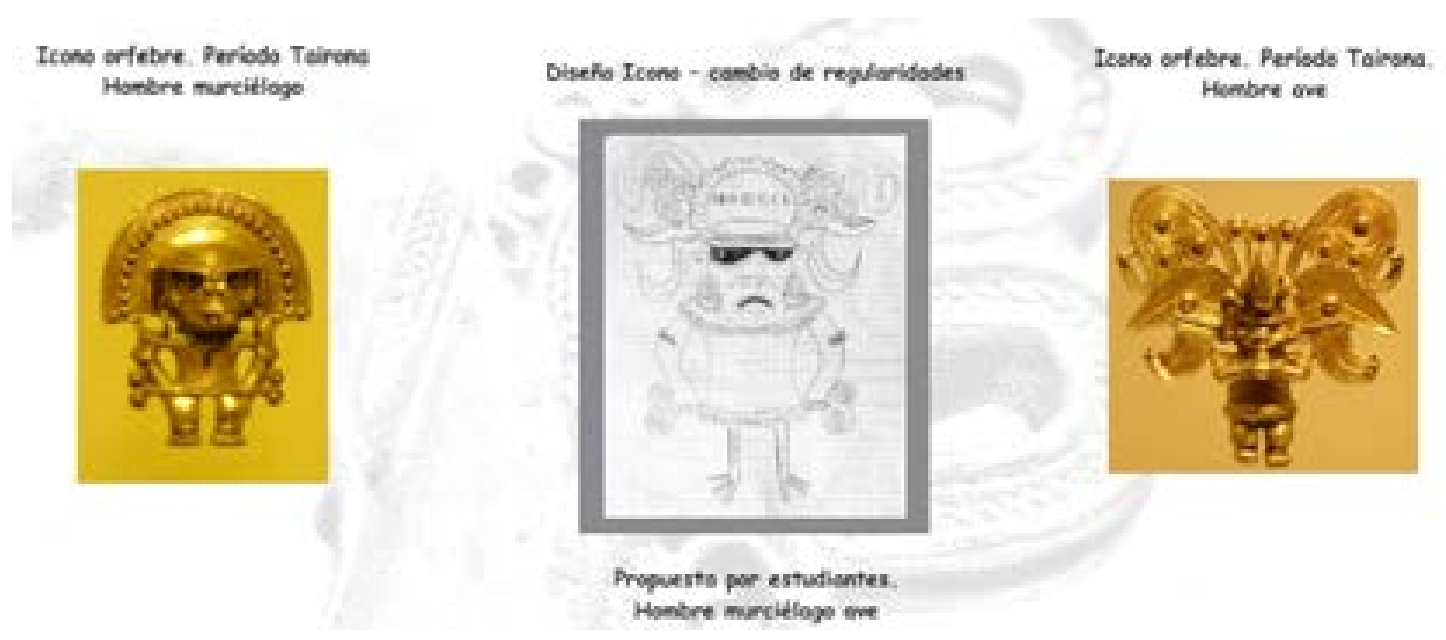

La práctica de identificación y uso de regularidades y patrones es transversal en el estudio de las matemáticas, siendo indispensable que se haga explícita para los profesores y los estudiantes de primeros semestres de pregrado, de tal forma que realicen el estudio sistemático; constituyendo, en dicha práctica, una manera de indagar en la estructura del sistema de numeración y medida decimal. De forma similar, ellas pueden potenciar la comprensión de conceptos estudiados en precálculo; como las escalas, la variación y al interior de ella la caracterización de funciones trascendentes (Vargas, 2019; Vargas, Chavés y Jaimes, 2018).

\section{A MANERA DE CONCLUSIONES}

La riqueza del trabajo interdisciplinario permite presentar esta propuesta, la cual desde una única disciplina de estudio sería muy difícil de lograr; en especial con el nivel de experticia que esta exige, para intentar acercarse a la comprensión del fenómeno como un todo. De allí que coincidamos con los autores que invitan a ir más allá de las disciplinas, al centrarse en un problema.

El video concerniente a regularidades y patrones de repetición en la cultura precolombina Tairona, es una pieza única, que se pone al servicio de docentes interesados en el tema a través del vínculo que se presenta en el desarrollo del artículo y de manera similar en las publicaciones posteriores (Vargas, Vargas y Castro, En Prensa).

La rúbrica que es un instrumento usual en educación; aquí marca unas pautas para para el seguimiento a la participación de los estudiantes en medio de sus compromisos mutuos y empresas en continuo cambio.

Agradecimiento a las Universidades Colegio Mayor de Cundinamarca de Colombia y Salamanca de España. Al igual que a la maestra de artes plásticas Nury Vargas Hernández, por la creación y diseño del video central y la toma de fotografías de los objetos orfebres del Museo del Oro, Bogotá -Colombia, seleccionados y utilizados para la investigación, como miembro de este grupo de investigación BIOMA. Reconocimiento al docente Rafael Felipe Chaves Escobar en la revisión del proyecto inicial, con este grupo de investigación. 


\section{REFERENTES BIBLIOGRÁFICOS}

Camargo, L. (2010). Descripción y análisis de un caso de enseñanza y aprendizaje de la demostración en una comunidad de práctica de futuros profesores de matemáticas de educación secundaria. Disertación doctoral. España: Universidad de Valencia

Castro, E. (1995). Exploración de patrones numéricos mediante configuraciones puntuales. Tesis Doctoral. Granada: Universidad de Granada.

Grass, A. (1979). Animales mitológicos. Litografía Arco, Ciudad de Edición Bogotá, Colombia

Grass, A. (1982). Los rostros del pasado. Diseño prehispánico colombiano. /The Faces of the Past: Pre-Hispanic Colombian Design. Litografía Arco, Ciudad de Edición Bogotá, Colombia

Merino, E., Cañadas, M., Molina, M. (2013). Uso de representaciones y patrones por alumnos de educación primaria en una tarea de generalización. Edma 0-6: Educación Matemática en la infancia, 2(1), 24-40.

Reichel -Dolmatoff, G. (2005). Orfebrería y Chamanismo. Un estudio iconográfico del Museo del Oro del Banco de la República, Colombia. Banco de la República, Museo del Oro Bogotá D.C., Villegas Editores.

Lave, J., y Wenger, E. (1991). Situated learning. Legitimate peripheral participation. Cambridge: University Press. Meel, D. (2003)

Legast, A. (1987). El animal en el mundo mítico Tairona. Fundación de Investigaciones Arqueológicas Nacionales Banco de la República. Bogotá, Colombia.

López, P., \& Betancourt, C. (2008). Argumentos inductivos. El ámbito de la probabilidad.

Lleras, R. (2015). Representación y simbología en el arte prehispánico. En: Credencial Historia. Arte en Colombia. No, 308.
Recuperado de http://www.banrepcultural. org/biblioteca-virtual/credencial-historia/ numero-308/representacion-y-simbologiaen-el-arte-prehispanico

Gutiérrez, L \& Torres, M. (2009). Vuelo mágico de Orión y los animales mitológicos. Un estudio del arte simbólico precolombino de Colombia. Viento ediciones.

Read, H.(1990). Arte y Sociedad. Ediciones Península, Madrid.

Reichel-Dolmatoff, G. (2005). Orfebrería y Chamanismo. Un estudio iconográfico del Museo del Oro del Banco de la República de Colombia. Villegas Editores: Colombia.

Rivadeneira, R. (2015). Lo Maravilloso del Arte Indígena. Revista Credencial Historia No. $3072015-07-13$.

Sondereguer, C. (2000). Diseño precolombino. Catálogo de iconografía: Mesoamérica, Centroamérica, Suramérica. Ediciones G. Gili, SA: México.

Vargas, N. Cáceres M,J., Vargas, J. (2018). Mathematics and art: pre-columbian figures in pre-calculus proportion's study. Investigación en educación matemática XXII. En: España Ediciones de la universidad de Oviedo. p. 666.

Vargas, J. (2019). Enseñanza de la función exponencial. Investigación y práctica en el aula: de la Primaria al Precálculo en la Universidad. Bogotá: Sello Editorial Universidad Colegio Mayor de Cundinamarca.

Vargas, J., Chavés, R. F., \& Jaimes, L. A. (2018). Sensores y Apps en el estudio de la escala logaritmica. Revista LOGOS, ciencia y tecnologia. 10(1). p. $129-144$.

Vargas, J., Vargas, N., y Castro, J.J. (sin publicar). Las prácticas matemáticas de identificación de patrones: docencia y arte precolombino. 
Vargas, N (2018). Regularidades y patrones imagen del hombre murciélago cultura tairona. https://www.youtube.com/ watch?v=6uQ98wJoJdg. Visitada el 02-102020. DOI: $10.13140 / R G .2 .2 .27730 .40643$

Vargas, N. y Vargas, J. (2019). Arte y Matemáticas. El caso de regularidades y patrones en la cultura precolombina para la enseñanza en precalculo. En: Champaign, Illinois, EE.UU. por Common Ground Research Networks, NFP.p. 58.

Vásquez, S. (2011). Comunidades de práctica. EDUCAR, 47 (1), 51-68.

Wenger, E. (1998). Comminities of practice. Learning, meaming and identity. Cambridge, Cambridge University.

Wenger E. (2001). Comunidades de práctica, aprendizaje, significado e identidad. Barcelona: Paidós. 